\title{
Modelling and characterisation of the high-rate behaviour of rock material
}

\author{
Simon Larsson ${ }^{1}{ }^{*}$, Masahiro Nishida ${ }^{2}$, Shuhei Kurano ${ }^{2}$, Tomoki Moroe ${ }^{2}$, Gustaf Gustafsson ${ }^{1}$, Hans-Ake Häggblad ${ }^{1}$, and Pär \\ Jonsén ${ }^{1}$ \\ ${ }^{1}$ Luleå University of Technology, Division of Mechanics of Solid Materials, SE-97187, Luleå, Sweden \\ ${ }^{2}$ Nagoya Institute of Technology, Gokiso-cho, Showa-ku, Aichi, 466-8555, Japan
}

\begin{abstract}
For future reliable numerical simulations of impact wear on steel structures caused by rock material, knowledge about the dynamic mechanical properties of rock material is required. This paper describes the experimental and numerical work to investigate the dynamic mechanical properties of diabase (dolerite), a subvolcanic rock material. In this study, diabase from southern Sweden was used. The impact compressive strength of diabase with a density of $2.63 \mathrm{~g} / \mathrm{cm} 3$ was examined by using the split-Hopkinson pressure bar (Kolsky bar) method. Cylindrical specimens were used, with a diameter of $8.9 \mathrm{~mm}$ and a length of $14 \mathrm{~mm}$. To characterise the rock material, uniaxial compression tests were performed, at high strain rates (150 s-1). Using an inverse modelling approach, material parameters for an elastic constitutive model, with a stress-based fracture criterion were determined. The constitutive model was used in a finite element simulation of a high strain rate uniaxial compression test. Results obtained from the numerical model were in line with the experimental results.
\end{abstract}

\section{Introduction}

Diabase (dolerite), a subvolcanic rock material, is a very commonly used construction material. During excavation, diabase is loaded and transported mainly on trucks. While loading, the truck beds are exposed to impacts, often resulting in severe impact wear. To better predict the wear life of the truck beds the mechanical behaviour of both the steel and rock must be known. The prediction of wear in dumper truck beds was studied in [1]. The authors concluded that further measurements of the dynamic mechanical properties of the rock materials were required to improve the wear models. Previous experimental investigation has shown that the mechanical characteristics and fracture of diabase are strongly dependent on the strain rate [2].

The authors' group has been studying strain rate sensitivity and failure strength experimentally for a variety of materials. Furthermore, the experimental studies have been used for characterization and modelling of high strain-rate loaded materials [3-6].

In this study, the dynamic mechanical properties of diabase, subjected to high strain rate loading, were investigated experimentally and numerically. A methodology for determining material parameters for an elastic constitutive model for diabase, with a stress-based fracture criterion, was developed. The material parameters were determined from experimental splitHopkinson pressure bar (SHPB) results and a finite element (FE) model of the same experiment, using an inverse modelling approach.

\section{SHPB test}

\subsection{Experimental setup}

At high strain rates of $150 \mathrm{~s}^{-1}$, rock material, diabase from southern Sweden, was compressed by the SHPB (Kolsky bar) method [7-8]. The diabase had a density of $2.63 \mathrm{~g} / \mathrm{cm}^{3}$. The input and output bars were made of steel S45C with a Young's modulus of $205 \mathrm{GPa}$ and a density of $7.7 \mathrm{~g} / \mathrm{cm}^{3}$. The input and output bars had a diameter of $16 \mathrm{~mm}$ and a length of $2300 \mathrm{~mm}$ and $1700 \mathrm{~mm}$, respectively. Strain gauges were placed on the input and output bars at distances of $1250 \mathrm{~mm}$ and $850 \mathrm{~mm}$ from the specimen. A striker made of brass with a diameter of $14 \mathrm{~mm}$ and a length of $350 \mathrm{~mm}$ was used. A sketch of the experimental setup is shown in Fig. 1. Uniaxial compression tests were carried out using diabase specimens with a diameter of $8.9 \mathrm{~mm}$ and length of 14 mm, see Fig. 2.

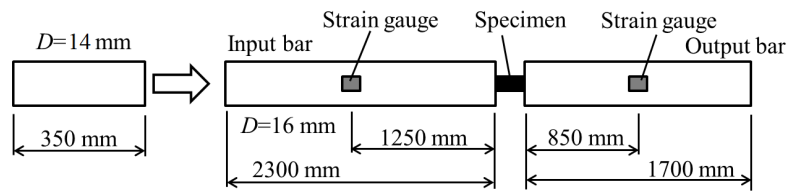

Fig. 1. Experimental setup for the split-Hopkinson pressure bar method. 


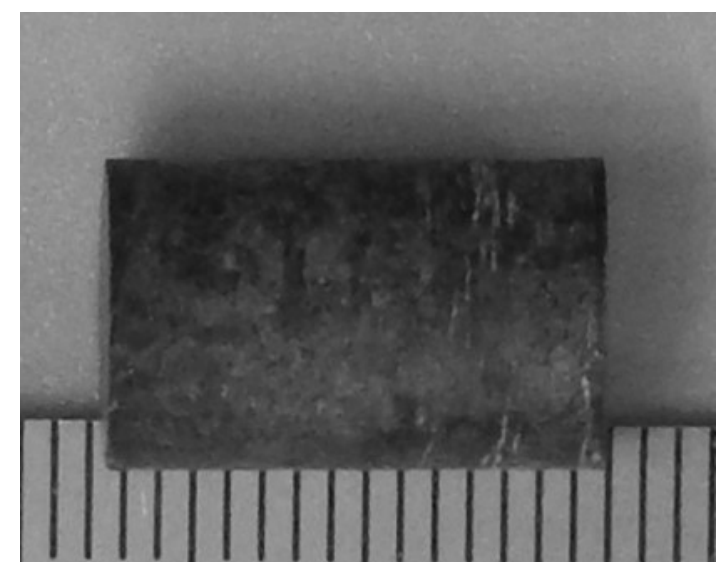

Fig. 2. Diabase specimen used for split-Hopkinson pressure bar experiment.

The nominal stress time history of the specimens $\sigma(t)$ was calculated using the following equation [3].

$$
\sigma(t)=\frac{A E}{A_{s}} \varepsilon_{T}(t)
$$

In Equation (1), $\mathrm{A}$ is the cross-sectional area of the output bar, E is the Young's modulus of the bar, $A_{S}$ is the cross-sectional area of the specimen and $\varepsilon_{\mathrm{T}}(t)$ denote the axial strain time history transmitted in the output bar.

\subsection{FEM simulation}

The commercial nonlinear FE code LS-DYNA version R10.0 [9] was used for the numerical modelling and simulation of the SHPB test. The FE model of the SHPB test included the input/output bars and the specimen. The striker was excluded from the model. Instead of modelling the striker, a velocity was applied to the nodes on the left end of the input bar. This velocity was determined from the SHPB test. By this procedure, the incident wave used in the simulations was the same as in the experiments. The SHPB test was modelled as a threedimensional FE model, using eight-node hexahedral solid elements. Explicit time integration was used for the simulations. The steel material of the input/output bars was modelled as a linear elastic material. The diabase specimen was modelled as a linear elastic material coupled with an element erosion criterion. The element erosion was governed by an equivalent stress at failure. When the equivalent stress at failure is reached in a solid element, it is removed from the simulation. The bars were represented with 20 solid elements in the circumferential direction and 460 and 340 elements in the axial direction for the input and output bars respectively, see Fig. 3. The diabase specimen was represented using 60 elements in the circumferential and axial directions, resulting in a total of 63900 solid elements, see Fig. 4. Small elements were needed in the modelling of the specimen to accurately represent the material failure using the proposed element erosion criterion. Contact between the bars and the specimen was realised using a penalty-based contact algorithm, where a constant coefficient of friction of 0.3 was used.

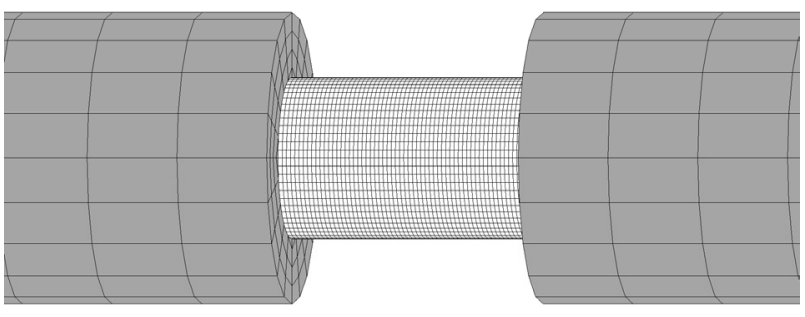

Fig. 3. Finite element model of the split-Hopkinson pressure bar experiment, zoomed in close to the specimen.

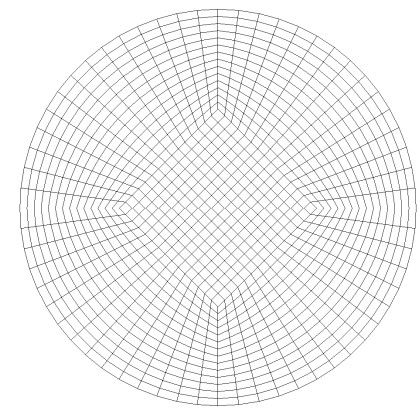

(a) Top view.

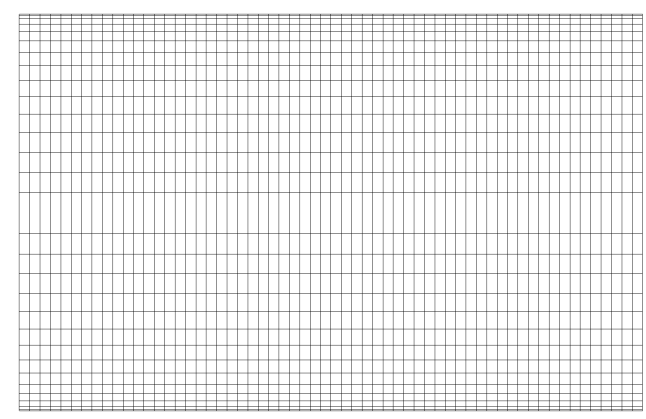

(b) Side view.

Fig. 4. Finite element model of the diabase specimen.

\section{Results and discussion}

The Young's modulus of diabase was determined experimentally to $15 \mathrm{GPa}$. The Poisson's ratio was chosen to 0.2 , a typical value for diabase. By inverse modelling, comparing the simulated and experimental output bar strain, the value of the equivalent stress (von Mises effective stress) at failure was determined to 300 $\mathrm{MPa}$, for the actual strain rate $\left(150 \mathrm{~s}^{-1}\right)$. The measured strain in the input bar for the SHPB test was used to obtain the velocity of the incident wave, used in the FE model, see Fig. 5.

The experimental and simulated strain histories in the output bar are compared in Fig. 6, showing an adequate agreement. The nominal stress time history in the specimen was calculated using Eq. (1), for both experimental and simulated strains. The stress time history was also determined from the FE simulation, by taking the average of the true stress in the central part of the specimen, see Fig. 7 for a comparison. 
Due to the small strains in the diabase specimen, the true and nominal stresses are approximately equal. Furthermore, the stress time histories obtained from the simulation shows a good agreement when compared to the experimental result.

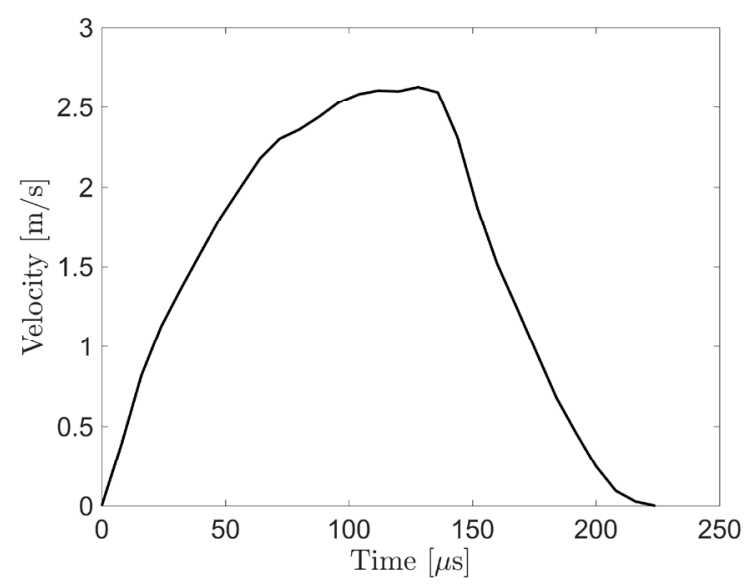

Fig. 5. Velocity applied to the nodes on the left end of the input bar in the simulation of the SHPB test.

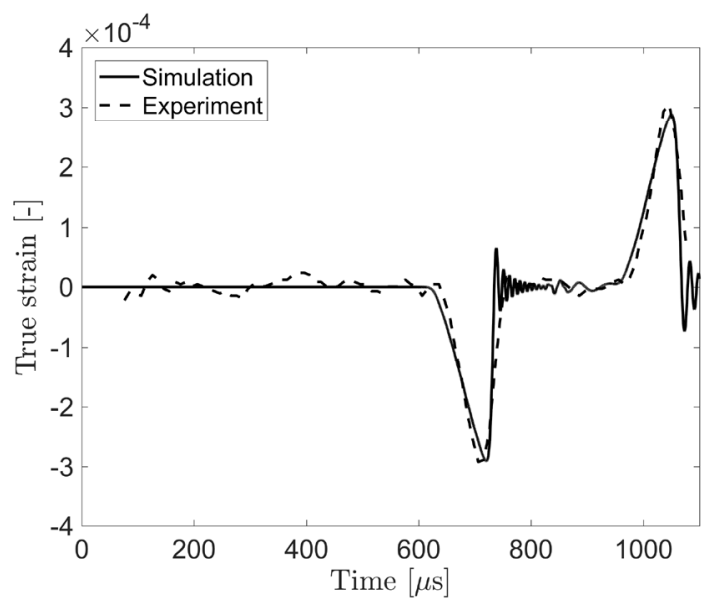

Fig. 6. Comparison between simulation and experiment of output bar strain time history.

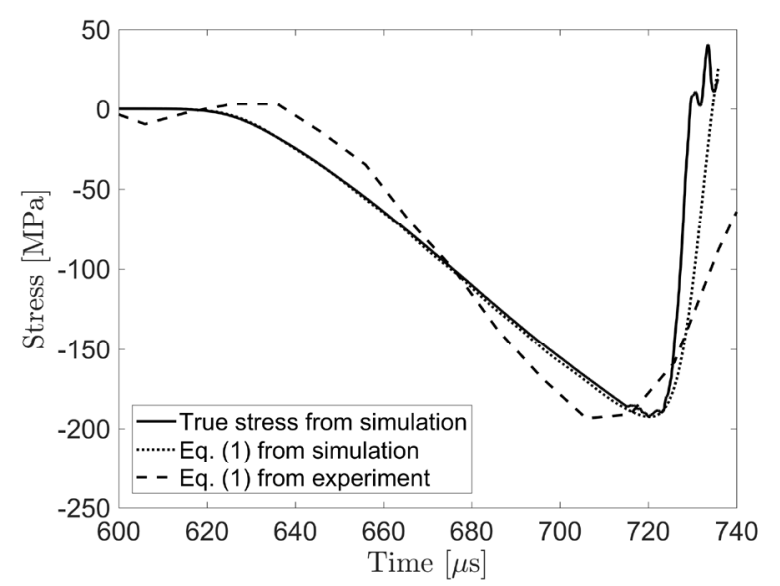

Fig. 7. Comparison between experiment and simulation of the stress time history in the specimen. The stress time history was obtained from an average of the element stresses in the specimen, and by calculation using Eq. (1), with simulated and experimental strain history as input.

The strain rate in the specimen was obtained from the simulation, see Fig. 8. The simulated strain rate is in good agreement to the strain rate of $150 \mathrm{~s}^{-1}$ used in the SHPB experiment. Thus, the numerical model can reproduce experimental high strain rate loading of the specimen. In Fig. 9, the simulated crack (eroded elements) is shown at the time $550 \mu \mathrm{s}$. At this time, the crack has propagated through the entire diameter of the specimen.

In the present study, the equivalent stress at failure was determined for one strain rate of $150 \mathrm{~s}^{-1}$. The proposed linear elastic model with failure captures the dynamic mechanical behaviour observed in the SHPB tests. Thus, the proposed methodology can be used to find the equivalent stress at failure for other strain rates.

The failure criterion used in the present study can be set to be a function of the strain rate. Thus, if the strain rate dependency of the diabase was investigated using the SHPB test, it could be readily included in the simulation model.

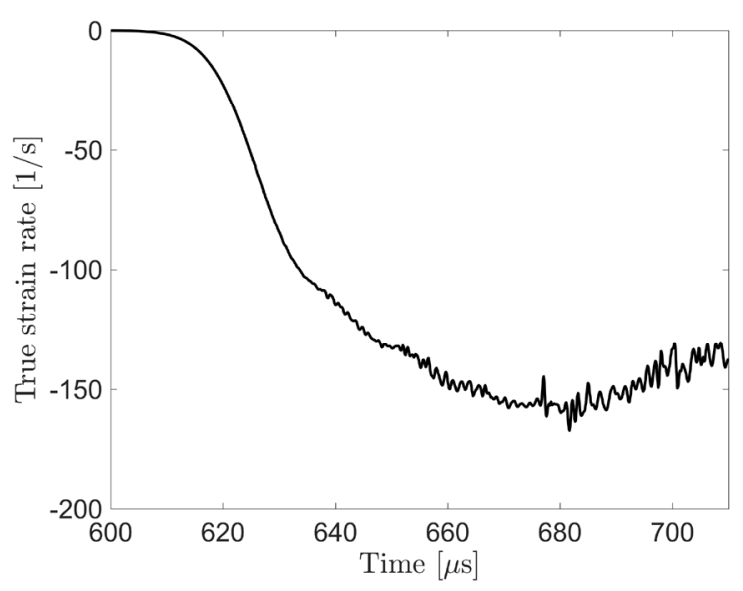

Fig. 8. Simulated true strain rate time history in the specimen, obtained from the averaged values in the central part of the specimen.

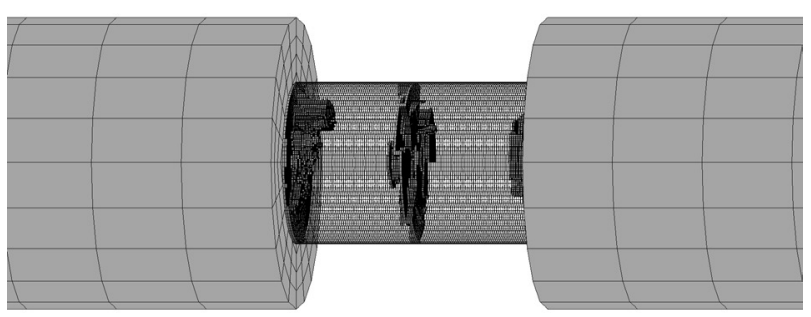

Fig. 9. Eroded elements in the specimen at $\mathrm{t}=550 \mu \mathrm{s}$.

\section{Conclusions}

The dynamic mechanical properties of diabase originating from southern Sweden have been investigated experimentally and numerically. A methodology for determining material parameters for rock materials at high rate loading has been proposed. 
Experimental results from a SHPB test and a FE model of the same test were used to determine the material parameters of diabase, using an inverse modelling approach. Results obtained from the numerical model were in line with the experimental results, at the investigated strain rate. The proposed methodology can be used to establish and model strain rate dependent mechanical properties of rock material.

For financial support of the HARSHWORK project, the European Institute of Innovation and Technology (EIT) Raw Materials is gratefully acknowledged. For the financial support of the Horizon 2020 project "Development of smart and flexible freight wagons and facilities for improved transport of granular multimaterials", project id: 636520, the European Commission is gratefully acknowledged.

\section{References}

1. D. Forsström, T. Lindbäck, P. Jonsén, Tribology Materials, Surfaces \& Interfaces. 8, 111-115 (2014)

2. Y. Petrov, A. Bragov, A. Evstifeev, E. Cadoni, EPJ Web of Conferences. 94, 01042 (2015)
3. G. Gustafsson, M. Nishida, H.-Å. Häggblad, H. Kato, P. Jonsén, T. Ogura, Powder Technol. 268, 293-305 (2014)

4. G. Gustafsson, M. Nishida, Y. Ito, H.-Å. Häggblad, P. Jonsén, T. Takayama, M. Todo, J. Mech. Behav. Biomed. 51, 279-290 (2015)

5. Y. Kuroyanagi, M. Nishida, T. Ogura, H.-Å. Häggblad, P. Jonsén, G. Gustafsson, EPJ Web of Conferences. 94, 01060 (2015)

6. M. Nishida, Y. Kuroyanagi, H.-A. Häggblad, P. Jonsén, G. Gustafsson, EPJ Web of Conferences. 94, 01069 (2015)

7. G.T. Gray III, Classic Split Hopkinson Pressure Bar Testing, in ASM Handbook, Vol. 8, Mechanical Testing and Evaluation, 462-476 (ASM International, Ohio, 2000)

8. W. Chen, B. Song, Split Hopkinson (Kolsky) Bar: Design, Testing and Applications (Springer, Boston, 2010)

9. LSTC, LS-DYNA Keyword's User Manual version R10.0 (LSTC, Livermore, 2017) 